\title{
Retraction Note: Research on tropical ocean sea temperature based on big data and marine food cooking skills in coastal cities
}

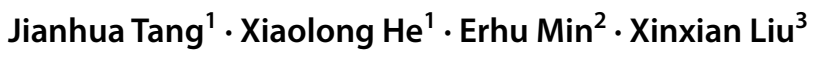 \\ Published online: 18 November 2021 \\ (c) Saudi Society for Geosciences 2021
}

Retraction Note: Arabian Journal of Geosciences (2021) 14: 1812 https://doi.org/10.1007/s12517-021-08115-x

The Editor-in-Chief and the Publisher have retracted this article because the content of this article is nonsensical. The peer review process was not carried out in accordance with the Publisher's peer review policy. Authors Jianhua Tang, Erhu Min and Xinxian Liu have not responded to correspondence regarding this retraction. The Publisher has not been able to obtain a current email address for author Xiaolong He.

The original article can be found online at https://doi.org/10.1007/ s12517-021-08115-x.

Jianhua Tang

tang13585231483@163.com

1 School of Tourism and Culinary Science, Yangzhou University, Yangzhou 225127, China

2 Jiangsu College of Tourism, Yangzhou 225127, Jiangsu, China

3 Shandong Weihai Jiulongsheng Hotel Management Co., Ltd., Shandong 264200, China 